\title{
A simple method for extraction of Ricinus communis L. oil and its application for biodiesel production by ethylic route
}

\author{
Jana Eduarda Alberto Vasco ${ }^{1}$. Paulino Sabite ${ }^{2}$. Estevão Clavel ${ }^{1}$. Esau Carlos Bandali ${ }^{1}$. Geraldo Alfredo Gueze ${ }^{1}$. \\ Domingos Augusto João ${ }^{1}$. Almeida Meque Gomundanhe ${ }^{1} \cdot$ Neuana Fernando Neuana ${ }^{1}$
}

Received: 18 December 2020 / Accepted: 13 February 2021

(c) The Author(s) $2021 \quad$ OPEN

\begin{abstract}
Biodiesel is a clean fuel, and an alternative to the environmental complications ascribed to fossil fuels. However, the forms of its production are still the object of research in the literature because some issues related to its process improvement and economical viability remain a challenge. Consequently, this research aims to produce biodiesel by the ethylic route from Ricinus communis $L$. oil extracted with a simple solid liquid extraction method without the use of the soxhled extractor and inspired from rural communities practices. In this sense, Ricinus communis $L$. was extracted by $n$-hexane as solvent, obtaining biodiesel through ethyl transesterification via alkaline catalysis. The characterization of biodiesel in terms of-acid value (AV), combustibility and corrosivity to copper. The results indicated that the yield of the extracted oil was $14 \%$ in relation to the mass of seeds used, the value of the $A \bigvee$ was $0.96 \mathrm{mg} \mathrm{NaOH} / \mathrm{g}$, showing in this case that the oil can be used in the transesterification process to obtain biodiesel. The biodiesel yield obtained was $37 \%$ and the AV was $1.98 \mathrm{mg} \mathrm{NaOH} / \mathrm{g}$, being considered above the acceptable value for its use in diesel engines, and should be neutralized to at least $0.8 \mathrm{mg} \mathrm{NaOH} / \mathrm{g}$. Based on this work, biodiesel was obtained via ethyl esterification of Ricinus communis L. oil extracted from a simple and easy method.
\end{abstract}

Keywords Biodiesel · Oil · Ricinus communis L. Extraction · Transesterification

\section{Introduction}

Biodiesel is fuel from biomass; this is renewable, clean, biodegradable, non-toxic, sulfur free among other advantages. For these reasons, it is considered the promisor fuel to overcome most of challenges ascribed to fuel from crude oil [1, 2]. Besides that, in its structure, it possesses oxygen atoms resulting in enhancement combustion process. As consequence, the combustion reaction is complete, avoiding the production of high quantities of carbon monoxide (CO), unburned hydrocarbons and particulate matters [3, 4]. Generally, biodiesel is produced from transesterification reaction of vegetal oils and other oils. In addition, in the biodiesel production, Fur glycerin is also produced as byproduct [5, 6]. Several crops such as, sunflower, coconut and others are used as a source of biodiesel. However, the oils from abovementioned crops are expensive and compete with areas for food productions. Thus, non-edible source of oils are the paramount for biodiesel productions. There are several types of non-edible crops for oil production [7]. The Ricinus communis L., belongs to the family Euphorbiaceae, it can nowadays be found in most of tropical countries [8]. The seeds of Ricinus communis, are generally used for biodiesel productions, because they allow an easy production [7-10]. Soxhalet and solvent extraction are commonly used for Ricinus communis L. oils production. The yields in terms of oils is better than

Neuana Fernando Neuana, neuananeuana1988@gmail.com | 'Department of Science, Engineering, Technology and Mathematics, University of Rovuma, Lichinga, Mozambique. ${ }^{2}$ Agrarian Institute of Lichinga, Lichinga, Mozambique.

Discover Sustainability $\quad$ (2021) $2: 7 \quad$ https://doi.org/10.1007/s43621-021-00017-y 
other sources such as (soyben: 15-20\% (p/p), sunflower: $25-35 \%(p / p)$, colza: 38-46\% (p/p) e palm: 30-60\% (p/p) [12]. Furthermore, the biodiesel produced from Ricinus communis L. oil presents properties that are in agreement with the quality standard of biodiesel [13]. Many methods such as hydrodynamic cavitation are applied for biodiesel production. The hydrodynamic cavitation is an interesting method, because it allows the biodiesel with yields between 40 and $80 \%$ in only $100 \mathrm{~min}$ [11]. In addition, for biodiesel production two routes are the cited in the literature, ethylic and methylic. Generally, the methylic route is most used for biodiesel production from Ricinus communis L. oil. The use of methanol is more common than ethanol because of its low cost and high reactivity, but there is a growing interest in the use of ethanol because it is renewable, non-toxic and is safe $[14,15]$. Methanol is generally added in higher proportions than the stoichiometric ratio $(3: 1)$, to change the equilibrium position of the reaction towards the product side. However, this fact strongly increases the final cost of the process, due to the fact that expenses with methanol are higher [16].

The extraction of Ricinus communis L. oil, is mainly performed applying sophisticated techniques, such as, Soxhlet, $\mathrm{CO}_{2}$ supercritical fluid and among others $[17,18]$. However, as far as we known, no works in literature was found that applied a simple and traditional approach to obtain Ricinus communis L. oils for biodiesel production. This extraction method is mainly applied by rural communities in Mozambique and other countries to obtain Ricinus communis L. oil for application in traditional medicine.

Therefore, the present work aims to produce biodiesel by ethylic route using Ricinus communis L. oil extracted applying a simple method.

\section{Materials and methods}

\subsection{Materials}

Ricinus communis L. oil was produced applying a simple method. Ricinus communis L. seeds were collected in Lichinga, Mozambique. The following was used used in this process; $n$-hexane (Supra Solvs), 95\% diethyl ether (Rochelle Chemical); 99.9\% ethanol and 37\% HCl-RPE, Brande: CARLO ERBA. The tests for oil extraction and transesterification were carried out at the chemistry laboratory of Rovuma University and at Agrarian Institute of Lichinga, respectively.

\subsection{Methods}

Ricinus communis L. oil was extracted with a simple solid liquid extraction method without the use of the soxhled extractor.

\subsubsection{Collection and treatment of Ricinus communis L. seeds}

The Ricinus communis L. seeds were collected in the city of Lichinga. These seeds were harvested without regard to their varieties, in so doing; it was a random collection, as the Ricinus communis L. variety issue was not being studied. The seeds collected, firstly were peeled and dried at $25^{\circ} \mathrm{C}$. The dried and peeled seeds were then weighted and dried in oven ( $\varnothing 3871112-48 / 228 \mathrm{~V}-758 \mathrm{~W})$ at $70^{\circ} \mathrm{C}$ for $30 \mathrm{~min}$. Following this, the seeds were toasted at $60^{\circ} \mathrm{C}$ for $30 \mathrm{~min}$ and then weighed again. After drying, $600 \mathrm{~g}$ of dry seeds were weighed and crushed by mortar and pistil, until an oily and pasty mass was obtained.

\subsubsection{Solvent extraction of Ricinus communis L. oil}

The seeds treated in the previous step were mixed with hexane in 1:2 proportion (600 $\mathrm{g}$ of seeds to $300 \mathrm{~mL}$ of $n$-hexane). The mixture was heated at $68{ }^{\circ} \mathrm{C}$ for $10 \mathrm{~min}$ and was kept for $15 \mathrm{~h}$. After $15 \mathrm{~h}$ the oil mass was filtered through a paper filter coupled to a funnel, using an Erlenmeyer flask to collect the oil. The mixture containing oil and solvent was submitted to a vacuum evaporator under constant heating of $68^{\circ} \mathrm{C}$ for $50 \mathrm{~min}$. Thereafter, the oil was left to cool naturally and was kept in a glass container Fig. $6 c$. Finally, the amount of oil produced by seeds of Ricinus communis was evaluated by weighing the oil obtained compared to the initial weight of the seed (Eq. 1). 


$$
\text { Oil Yield }(\%)=\frac{\text { weight of oil }}{\text { weight of the seed }} \times 100 \%
$$

\subsection{Biodiesel production}

The production of biodiesel from Ricinus communis L. is based on the methodology proposed by [19]. Having changed some parameters such as the solvent. In this experiment $74 \mathrm{~g}$ of Ricinus communis $\mathrm{L}$. oil was used in the biodiesel production. Firstly, the oil was heated at $65-70^{\circ} \mathrm{C}$. In parallel experiment, an ethanolic solution containing $45 \mathrm{~mL}$ of ethanol and $1 \mathrm{~g}$ of $\mathrm{NaOH}$ was prepared, using magnetic stirrer, it was then necessary to elevate the temperature to $50^{\circ} \mathrm{C}$ for $48 \mathrm{~min}$. After the dissolution, of $\mathrm{NaOH}$, the solution was added to Ricinus communis $L$. The process was kept under constant stirring for $2 \mathrm{~h}$ at $70^{\circ} \mathrm{C}$. Figure 1 illustrates all the steps followed until biodiesel synthesis.

\subsubsection{Purification of the product obtained from transesterification}

The mixture of biodiesel and glycerol was removed from the funnel and heated to $80^{\circ} \mathrm{C}$ until it returned to a liquid state, after it had solidified. Subsequently, $2 \mathrm{~mL}$ of HCl was added to neutralize the catalyst used in the transesterification. Then the product was added back to the separating funnel and the biodiesel was separated from the glycerol. The biodiesel was washed with warm water until the washing water reached neutral $\mathrm{pH}$. The biodiesel yield was then calculated using Eq. 2.

$$
\text { Biodiesel yield }(\%)=\frac{\text { Total wt.of product produced }}{\text { wt. of. oil }} \times 100 \%
$$

The total weight $(\mathrm{g})$ of the biodiesel produced during transesterification was divided by the weight $(\mathrm{g})$ of the oil used as raw material to determine the production yield of biodiesel.

\subsection{Experimental characterization of biodiesel}

The biodiesel of ricinus communis was characterized by its physicochemical properties such as the acid value, combustibility test and corrosion test. The experimental procedures of each property are presented below.

Fig. 1 Resume illustration of all of the work steps

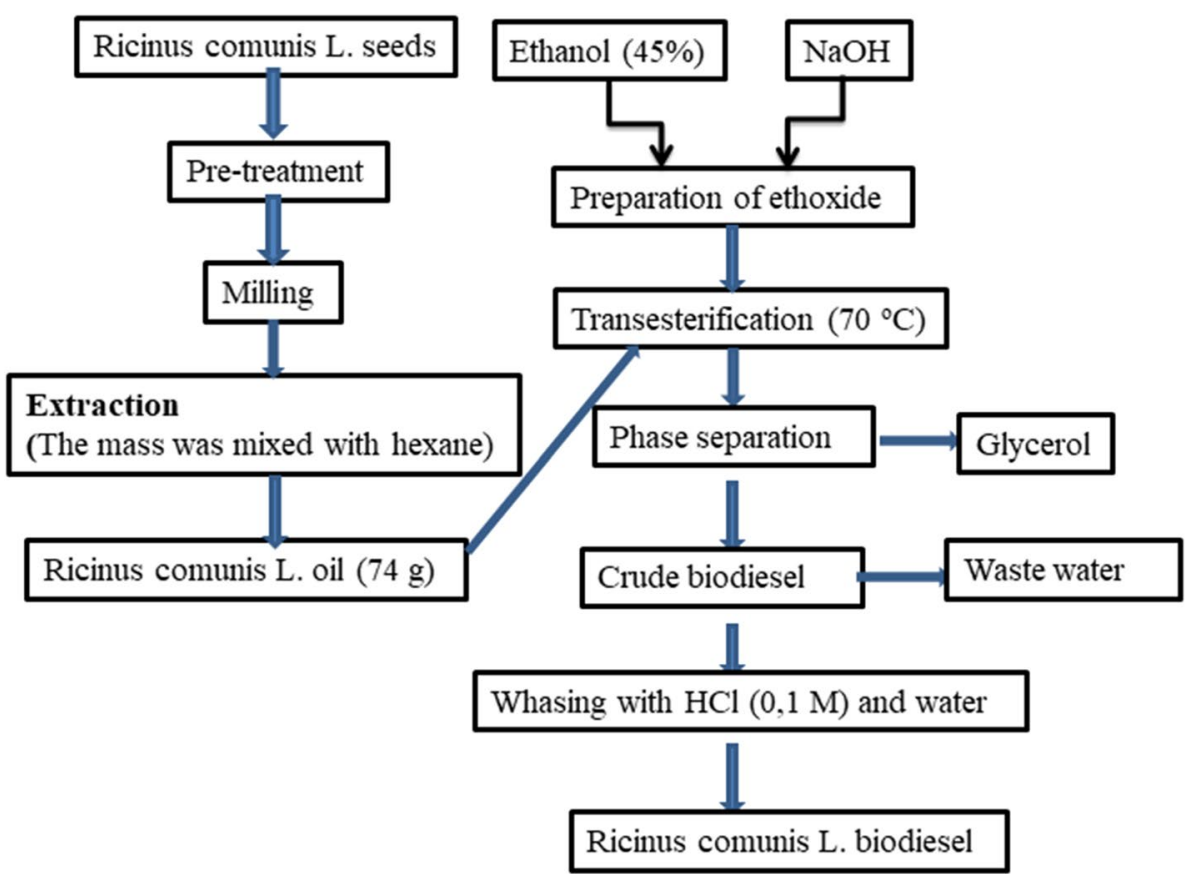




\subsubsection{Determination of acid value of Ricinus communis L. oil}

The acid value of Ricinus communis $\mathrm{L}$. oil was determined in triplicate. About $4.30 \mathrm{~g}$ of Ricinus communis $\mathrm{L}$ oil was placed in an Erlenmeyer flask, with $25 \mathrm{~mL}$ of ethyl ether/ethyl alcohol in a 2:1 (v/v) ratio, 3 drops of phenolphthalein and titrated with $0.1 \mathrm{KOH}$ solution $\mathrm{mol} \mathrm{L}^{-1}$. The same procedure was used to determine the acid value of biodiesel. The results obtained were compared with the values standardized in the standards described in Table 1. The acid value was determined using Eq. 3.

$$
\mathrm{AV}=\frac{(\mathrm{VNaOH}-\mathrm{Vwhite}) \times \text { Cbase } \times \text { MMbase }}{\text { Msample }}
$$

Being, $\mathrm{AV}=$ Acid value $(\mathrm{mg} \mathrm{NaOH} / \mathrm{g}) ; \mathrm{V}_{\mathrm{NaOH}}=$ Volume $(\mathrm{mL})$ of the $\mathrm{NaOH}$ solution spent on the titration; $\mathrm{V}_{\text {white }}=$ Volume of the titrant solution in $\mathrm{mL}$ for titration of the blank, $\mathrm{C}=$ Concentration of the titrant solution in $\mathrm{mol} \mathrm{L}^{-1} ; \mathrm{M}_{\text {sample }}=$ mass of the sample in grams.

\subsubsection{Combustibility test}

Four cotton pads were embedded separately with $3 \mathrm{~mL}$ of Ricinus communis $L$ oil $(\mathrm{OR}), 3 \mathrm{~mL}$ of Ricinus communis $\mathrm{L}$. biodiesel (BR), $3 \mathrm{~mL}$ of petroleum diesel (DP) and $3 \mathrm{~mL}$ of the mixture of $20 \%$ Ricinus communis L. biodiesel with petroleum diesel (B20), respectively. The pads were placed in porcelain crucibles (one crucible for each pad) identified as OR, biodiesel of Ricinus communis L. (BR), DP and B20. A matchstick was used as a heat source to see which one would be flammable and observation of the characteristics of its flame was made.

\subsubsection{Corrosion test}

Two copper wires were placed in beaker cups and the beakers were identified as BR and DP. $2 \mathrm{~mL}$ of Ricinus communis L. biodiesel was pipetted into the BR beaker until the copper wire was soaked. Following this, $2 \mathrm{~mL}$ of petroleum diesel was pipetted into the DP beaker until the copper wire was embedded. The mixtures were left to stand for $48 \mathrm{~h}$. After $48 \mathrm{~h}$ the wires were removed from the beakers and compared with the new wires (not used in the test-control).

\section{Results and discussion}

\subsection{Solvent extraction of Ricinus communis L. oil}

Figure 2 shows the results regarding seeds mass variation after two drying cycles. According to Fig. 2 , after the first drying procedure the seeds lost $8 \%$ mass compared to fresh seeds. Whereas, after the second drying procedure the mass loss was $9 \%$ in relation with fresh seeds. These results are yet expected because the fresh seeds present humidity and after drying a part of humidity was lost. Figure 3 shows a pasty mass after seeds pulverization. The formation of this pasty mass is due to high content of oil and the reduction of particle size allowing the interaction between particles. Furthermore, this step is particularly important because it allows the interaction between the grounded seeds with hexane.

Table 1 Comparison of different yields of Ricinus communis oil and biodiesel

\begin{tabular}{|c|c|c|c|}
\hline Biodiesel & Method/percentage of oil extracted & Yield (\%) & References \\
\hline \multirow[t]{4}{*}{ Biodiesel from Ricinus communis oil (Ricinus communis seed oil) } & $48 \%$ by soxhlet apparatus & 90 & {$[23]$} \\
\hline & $43.6 \%$ by soxhlet apparatus & 94 & {$[22]$} \\
\hline & $51.7 \%$ by Soxhlet extraction method & 61.44 & [29] \\
\hline & $\begin{array}{l}\text { 14\% A simple method for extraction by } \\
\text { solvent extraction. }\end{array}$ & 37 & This work \\
\hline
\end{tabular}


Fig. 2 Seed weight at different drying stages
Fig. 3 Product of crushing Ricinus communis $L$. seeds
Fig. 4 Ricinus communis L. oil extraction process. Aspects of the mixture before heating (a), after heating (b), $35 \mathrm{~min}$ after (c) and $15 \mathrm{~h}$ after (d)
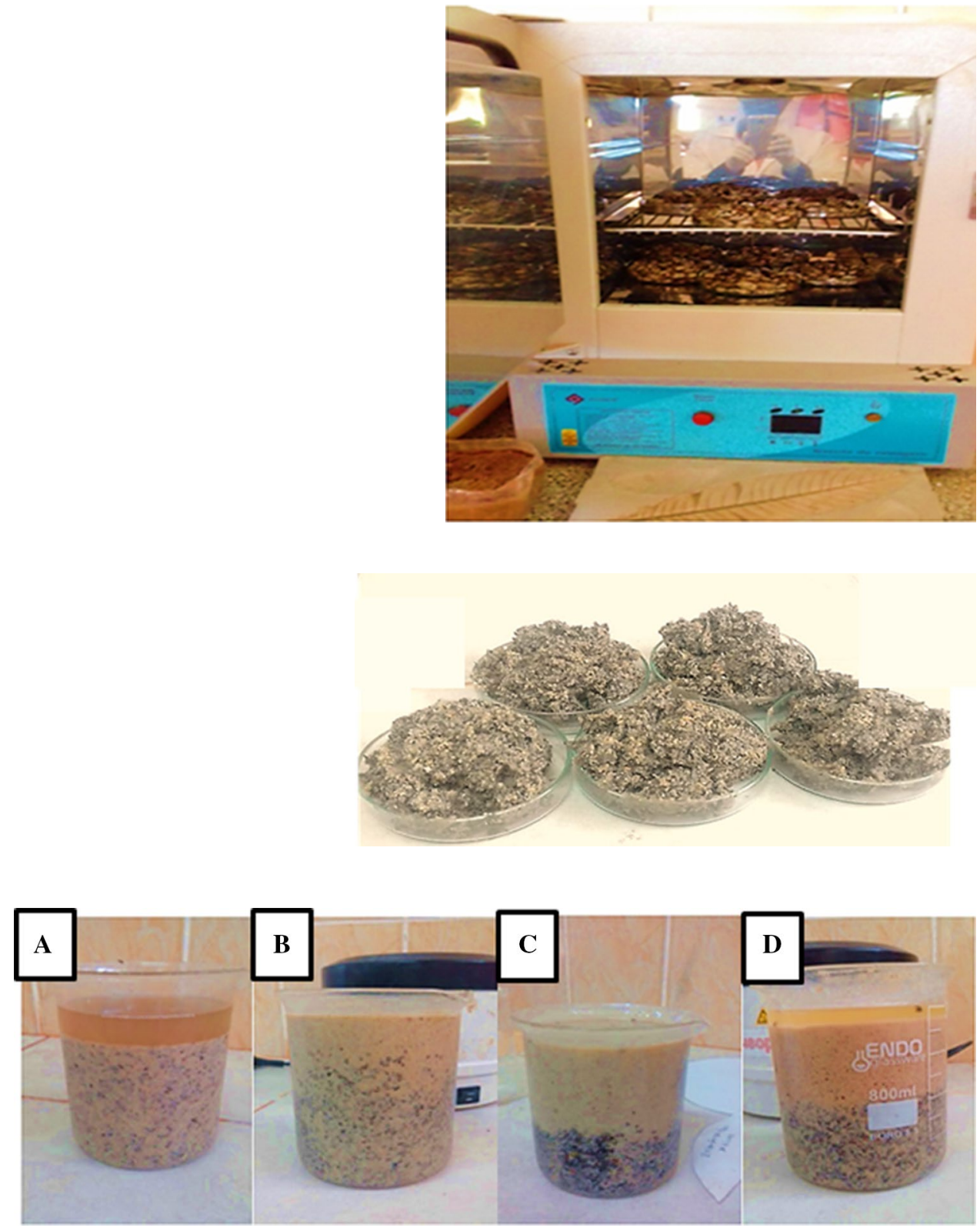

Figure 4 presents the macroscopically aspect of pulverized seeds in contact with hexane. In Fig. 4a, the phase separations are observable, suggesting that the solubilization had not started due to high viscosity of the mixture. Then, after the heating at $80^{\circ} \mathrm{C}$, the phase separations disappeared, forming a homogenous like mixture (Fig. $4 \mathrm{~b}$ ).

After $35 \mathrm{~min}$ (Fig. 4c), a separation into unstable oily phases could already be seen; these phases were stable and very visible when the mixture was left to stand for another $15 \mathrm{~h}$. The phenomena observed in (Fig. $4 \mathrm{~b}$ and c), is consequence of heating process that resulted in decrease of viscosity, leading to enhancement of dissolution of oil in hexane [20]. As a result, the extraction process accelerated. Subsequently, Fig. 4d, presents three phases after additional $15 \mathrm{~h}$. Phase 1 (from bottom to top) consisted of husks, thicker grains and contained less oil, phase 2 consisted of finer grains and contained a greater amount of oil compared to phase 1, and, finally, phase 3 consisted of oil and some seed grains.

Figure $4 \mathrm{~d}$ shows that in addition to the action of the solvent in this process, the granulometry also influenced a lot, since in each phase, particles with different granulometry were arranged and the phase with the highest granulometry (finer particles) has higher concentration of oils, which is why it is necessary to use the press to obtain finer grains in relation to those obtained in grinding, allowing a greater homogenization of the material to be extracted with the solvent, in addition to reducing the density of the flakes. 
Fig. 5 Process of filtering the mixture. Filtration (a, b), collection (c), Ricinus communis $\mathrm{L}$. oil collected $(\mathbf{d})$

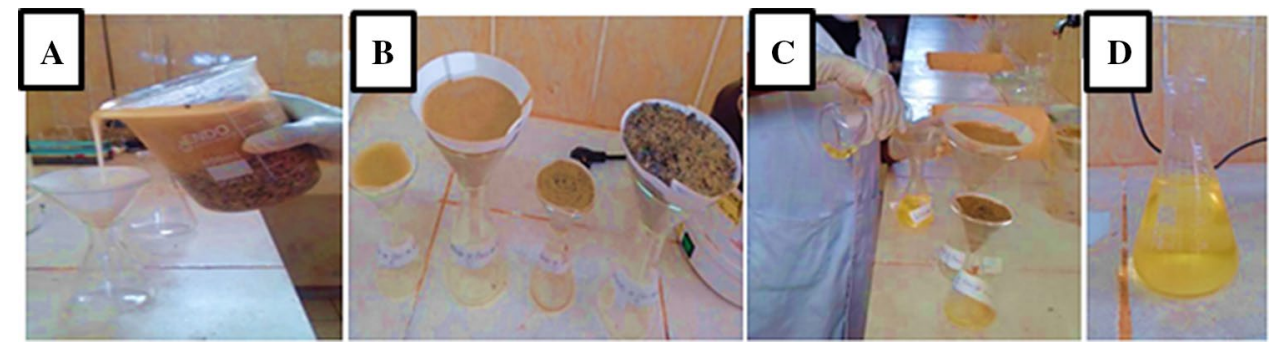

Fig. 6 Solvent elimination process in the oil. Beginning of the solvent elimination process (a), end of the process (b), final castor oil (c)

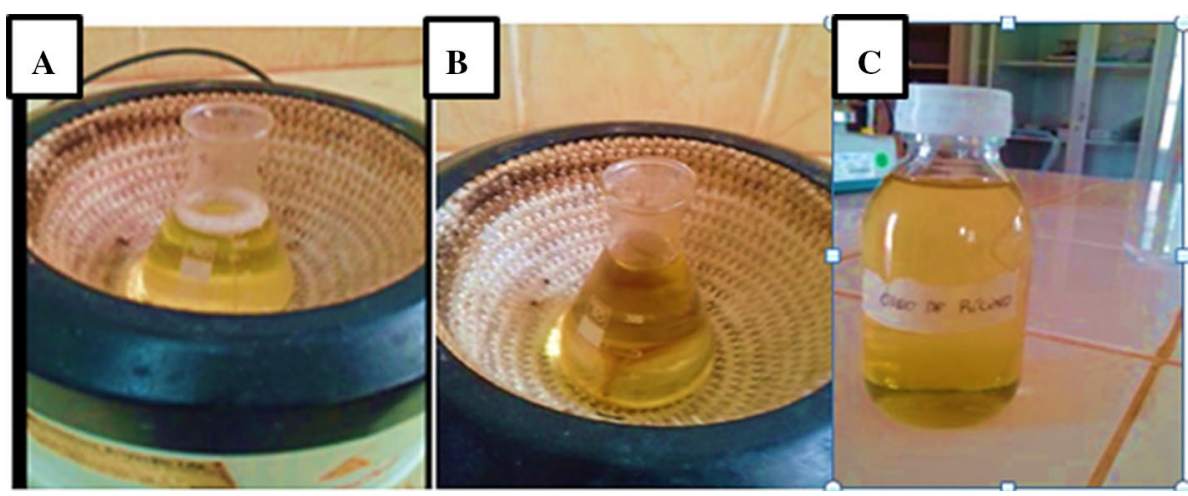

Figure 5a shows the upper part of the mixture being decanted into a filter paper attached to the long-stem funnel to start the filtration of the crude oil. In Fig. 5b, it is observed that all phases are being filtered under the same conditions. Figure $5 \mathrm{c}$ shows the filtered oil being collected into a single container, as the filtration was done separately due to the size of the materials used and due to the difference in appearance at each stage of the mixture, believing that this would facilitate the filtration of each phase. The crude oil can be seen in Fig. $5 \mathrm{~d}$.

When the flask containing the oil was left open for natural evaporation of the solvent, there was a reduction in viscosity resulting from the reduction of the solvent by evaporation, but the process was slow (it took a week to notice the difference in viscosity) therefore, the oil was subjected to evaporation under heating. During heating intense bubbles were formed (Fig. 6a). These bubbles were the result of the solvent being heated above its P.E, so the bubbles represented the boiling solvent. The bubbles reduced with the passage of time, until they disappeared completely (Fig. 6b), and the solvent elimination process ended. After removing the solvent, $75 \mathrm{~mL}$ of oil was obtained whose weight was $88.76 \mathrm{~g}$. In this case, the oil yield was $14 \%$ in relation to the mass of the seeds used (Fig. 6c).

By the method used to eliminate the solvent, it cannot be concluded that there was total elimination of the solvent in the oil, the most important being to ensure that there is a minimum of substances that can interfere in the transesterification process. Evaporation under continuous heating can be a good option when the solvent elimination process is to be efficient. However, care must be taken with the solvent used in the extraction process and the temperature to be used for heating.

\subsection{Biodiesel production}

\subsubsection{Ricinus communis L. oil transesterification}

The preparation of sodium ethoxide took $48 \mathrm{~min}$, as the dissolution of sodium hydroxide in ethyl alcohol was slow and the transesterification was maintained for $2 \mathrm{~h}$. During the addition of sodium ethoxide to the oil under heating and continuous stirring (Fig. 7c), there was an immediate change in the colour of the oil, which changed from light yellow to orange (Fig. $7 \mathrm{c}$ and d). In addition, it was observed that the oil became lighter. After $2 \mathrm{~h}$ of reaction, under constant stirring and heating, the process was stopped. When the product was placed in the separating funnel, it dried immediately, with no phase separation (Fig. 7d). this is due to the high value of free fatty acids that this oil presents, which in turn can make it difficult to separate phases after the transesterification reaction and can still cause problems with the formation of soap (saponification) [21] 
Fig. 7 Ethical transesterification of castor oil. Heating the oil (a), dissolving $\mathrm{NaOH}$ in ethanol (b), adding sodium ethoxide to the preheated oil (c), mixing during the reaction (d); phase separation (e)

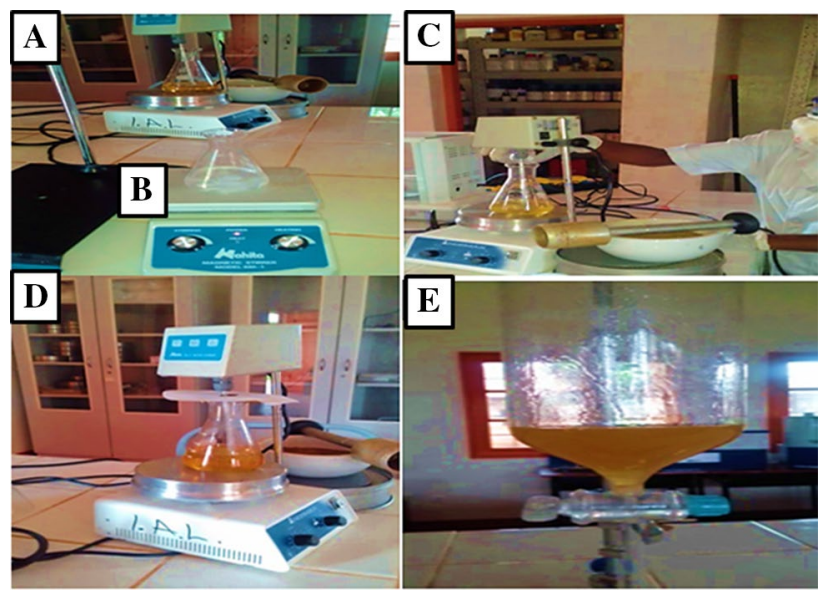

\subsubsection{Biodiesel purification}

The biodiesel was purified eliminating the excess of $\mathrm{NaOH}$ by titration. After the addition of $35 \% \mathrm{HCl}$ with the purpose of neutralizing the remaining catalyst and removing the salts of the product obtained in the transesterification process [12]. In the transesterification product, effervescence was registered which ended with the appearance of a white liquid which was separated by decantation. The final yield was $37 \%$ in relation to the OR mass used in transesterification. The final product of this process can be seen in Fig. 8d. Effervescence was the result of the reaction between hydrochloric acid $(\mathrm{HCl})$ and sodium hydroxide $(\mathrm{NaOH})$ used as a catalyst in transesterification. The production of Ricinus communis $L$ biodiesel requires higher level of control as it involves several parameters for the yield to be satisfactory [22, 23].

The yields shown in Table 1 refer to the conventional methods which involve a conventional reactor and the method of extracting oil from the seed of Ricinus communis $L$ oil, but for the research in question no conventional extraction method was used and the reactor used was of low cost. However, the biodiesel yield obtained was considered satisfactory under the conditions of the study.

\subsection{Physiochemical characteristics}

\subsubsection{Acid value}

The acid value of biodiesel was $1.98 \mathrm{mg} \mathrm{NaOH} / \mathrm{g}$, which shows an increase (Table 2). According to the norms of the ANP legislation, the established specification is that the acid value is between 0.1 and $0.5 \mathrm{mg} \mathrm{NaOH} / \mathrm{g}$ [24]. However, it is observed that, having the acid value of the oil as well as the biodiesel obtained, they presented values outside the established norm due to their high content of ricinoleic acid [9].

Fig. 8 Purification of the final product. Washing process (a-c); Final product obtained (d)

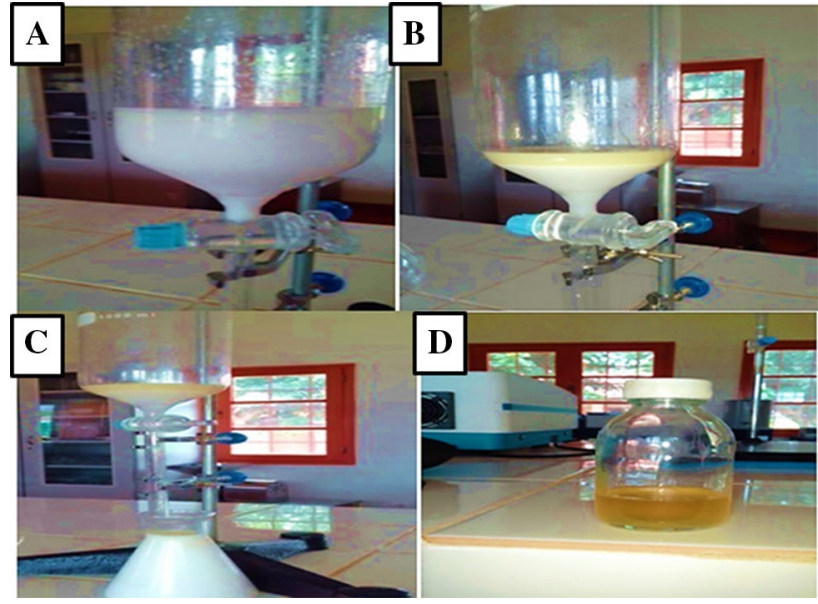


Table 2 Comparison between the acid value of the biodiesel obtained and the preestablished value in different countries

\begin{tabular}{lll}
\hline Sample & Value obtained & Maximum value established by the standards \\
\hline Acid value of Ricinus communis L. oil & \multirow{2}{*}{$1.98 \mathrm{mg} \mathrm{NaOH} / \mathrm{g}$} & $0.8 \mathrm{mg}$ Base/g-ANP 045/2014 (Brazil) \\
& & $0.5 \mathrm{mg}$ Base/g-EN 14214 (Europe) \\
& & $0.5 \mathrm{mg}$ Base $/ \mathrm{g}$ ASTM- D 6751 (EUA)
\end{tabular}

\subsubsection{Combustibility test}

Table 3 presents the phenomena observed in the combustibility test of Ricinus communis L. biodiesel. It compares combustibility of Ricinus communis $L$ oil with petroleum diesel, as well as the mixture between DP and BR. The flame intensity of the OR (Ricinus communis L. oil) was extremely low compared to that of the BR (Ricinus communis L. biodiesel) Table 3. It is suggested that these differences were influenced by the cetane number of each substance, which is a parameter directly associated with fuel combustibility, so with the transesterification there was an increase in the cetane number of Ricinus communis L. oil (converted into BR) [12]. Generally, the cetane number of biodiesel is much higher than that of mineral diesel, which justifies the fact that biodiesel has a more controlled ignition and burns better in the engine than mineral diesel oil itself [16]. On the other hand, the BR, DP and B20 flame were similar, with the advantage that the BR flame was controlled. Table 3 also presents that OR and DP showed a reduced flame duration than BR and BR 20. Being that the flame of the BR had a much longer extension and OR much smaller in relation to another sample (B20 and DP), with that it can be said that the BR is economical from the point of view of consumption in the engine, when compared with the DP.

Table 3, shows the smoke release behavior of all samples. There was a greater release of smoke in the burning of DP (oil diesel) and the mixture of DP and BR, having been lower in the mixture compared to pure DP, whereas in the BR a lower release of smoke was verified and when burning the OR the smoke release was not noticeable. Such aspects can be seen in Fig. 9.

Figure $9 \mathrm{~d}$, presents the feature after the burning process of oil diesel and Ricinus communis L. biodiesel, until the end of the process, the capsules that contained DP and B20 showed a greater amount of carbon black compared to

Table 3 Results obtained in the combustibility test of Ricinus communis L. biodiesel

Fig. 9 Combustibility test of castor biodiesel. Combustion starts (a), after $1 \mathrm{~min}$ and $44 \mathrm{~s}$ (b); at 2 min (c); after the end of combustion (d)

\begin{tabular}{|c|c|c|c|}
\hline Tested substances & Flame intensity & $\begin{array}{l}\text { Flame/time } \\
\text { extension }\end{array}$ & Smoke release \\
\hline Ricinus communis L. oil (OR) & Lower & Lower & Imperceptible \\
\hline Petroleum diesel (DP) & Very intense & Lower & Much smoke \\
\hline Ricinus communis $L$ biodiesel (BR) & Intense and controlled & Immense & Low smoke \\
\hline $\begin{array}{l}\text { Mixture of Ricinus communis L. bio- } \\
\text { diesel and petroleum diesel (B20) }\end{array}$ & Intense & Immense & $\begin{array}{l}\text { A lot of smoke, } \\
\text { however, less } \\
\text { than DP }\end{array}$ \\
\hline
\end{tabular}

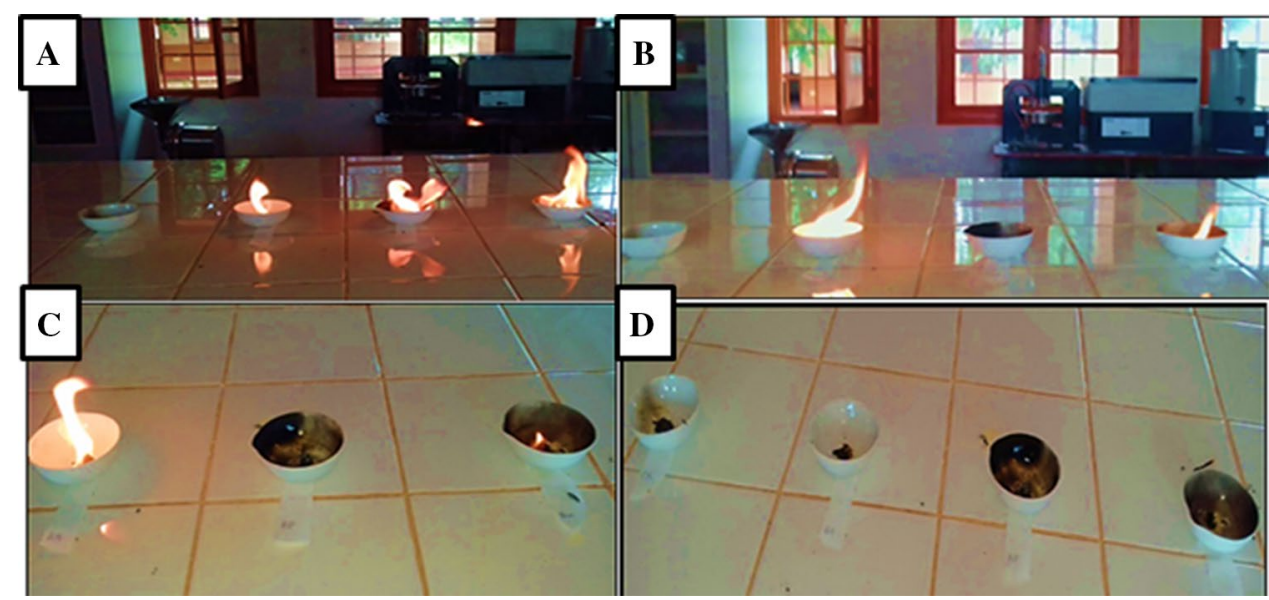


Fig. 10 Corrosion test of castor biodiesel. Copper wires before dipped in BR and DP (a); right after dipping (b); $48 \mathrm{~h}$ later (c)

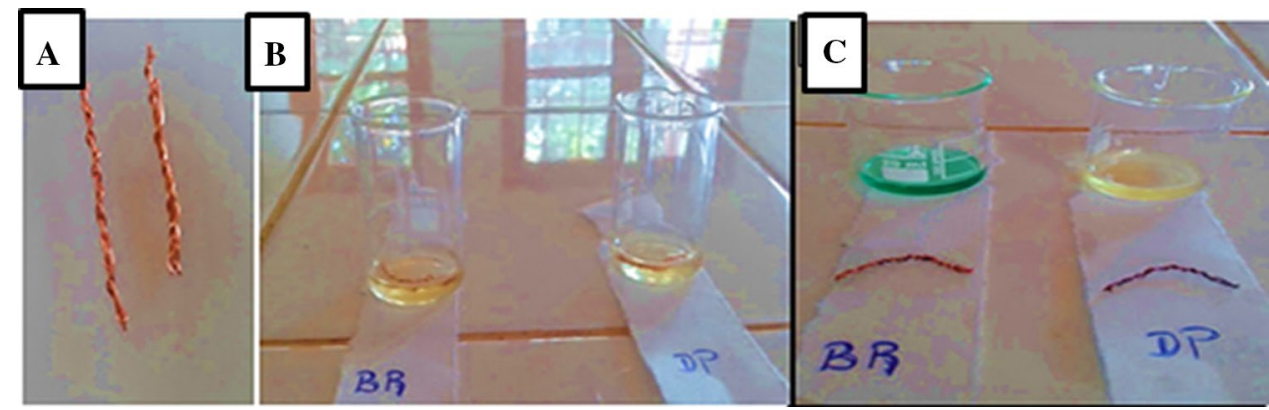

the capsule in which the BR was burned. BR, the presence of carbon black was practically not verified at the end of the process, a fact that demonstrates the advantage of using BR in terms of the impacts of emissions when compared to DP. In this way, these observations are in agreement with studies that reported that fuels like ethanol and biodiesel release less pollutants than crude oil derivatives [25].

\subsubsection{Corrodibility}

The corrosibility of Ricinus communis L. biodiesel was performed using copper as a model metal (Fig. 9c). The BR presented a green color after $48 \mathrm{~h}$ of copper. However, the DP did not change the color, but the copper was corroded. The BR changed the color due to the oxidation reaction caused by copper [26]. The BR possess double bonds in the structure that can easily break, originating reactive radicals that can react with $\mathrm{Cu}^{0}$ resulting in $\mathrm{Cu}^{2+}$ (green color). For these reasons, additives are necessary to inhibit the oxidation [27]. It can be seen from Fig. 10c, that DP did not change in colour, but the wire that was dipped in the DP turned black (Fig. 10b), showing stability from the point of view of corrosion stability. Diesel has a greater corrosion stability compared to biodiesel. For the corrosion to be observed in a diesel environment, the metal must be exposed for a long period of time, unlike biodiesel that oxidizes when exposed to air and high temperatures, forming organic acids and hydroperoxides, which impair the quality of the product and promote corrosive processes [28].

\section{Conclusions}

A simple and rural communities practices inspired extraction process was applied in Riccinus communis $L$ oil for biodiesel production. In this work, extraction with $n$-hexane proved to be efficient, since a yield of $14 \%$ was obtained in relation to the mass of seeds used in the process and the acid value $(0.69 \mathrm{mg} \mathrm{NaOH} / \mathrm{g})$, considering within standards for the transesterification process ( $\geq 3 \mathrm{mg} \mathrm{NaOH} / \mathrm{g}$ ). Biodiesel was obtained through the ethyl route with a yield of $37 \%$ in relation to the Ricinus communis L. oil mass, with an acid value of $1.98 \mathrm{mg} \mathrm{NaOH} / \mathrm{g}$, being outside the parameters of ANP 045, with the need to correct the acidity as that this oil has a high index of ricinoleic acid. The combustibility of Ricinus communis L. biodiesel was better than petroleum diesel. However, by the corrosivity test, biodiesel proved to be very unstable, having suffered a degradation that resulted in the oxidation of the copper wire. The results of the acid value of Ricinus communis L. biodiesel are in agreement with its effect on corrosivity under the same study conditions.

Acknowledgements The Rovuma University-Extension of Niassa for providing all support of laboratory infrastructure to carry out the research, likewise, we thank the Agrarian Institute of Lichinga (IAL) for the material support and laboratory infrastructure to produce castor biodiesel. We also thank, Domingos Lusitâneo Pier Macuvele, for its insightful comments in first and post submission of this manuscript.

Authors' contributions JEAV: Responsible for researching the theme of this article. PS: Guided all experimental activity of this work. EC: Prepared all the figures. ECB: Defined the objectives of the research. GAG: Organized the tables and compared the results of this research with other literature. DAJ: Wrote the summary and the conclusion of the work. AMG: Organized the work methodology. NFN: Supervised the work and wrote the manuscript. All authors read and approved the final manuscript.

Data availability All data were obtained from a simple and traditional approach to obtain Ricinus communis L. oils for the production of biodiesel. This extraction method is applied mainly by rural communities in Mozambique and other countries to obtain Ricinus communis L. oil for application in simple techniques of traditional medicine. These techniques do not generate computerized data. In this sense, we do not 
have the original files Dat, JPX, HTF, CSV, ABF, SPC, which are commonly generated by equipment such as GC-MS, FTIR, XDR. However, the data available in this work, are the same as we have in the notebooks and if requested we will be happy to provide.

Competing interests The authors declare no competing interests.

Open Access This article is licensed under a Creative Commons Attribution 4.0 International License, which permits use, sharing, adaptation, distribution and reproduction in any medium or format, as long as you give appropriate credit to the original author(s) and the source, provide a link to the Creative Commons licence, and indicate if changes were made. The images or other third party material in this article are included in the article's Creative Commons licence, unless indicated otherwise in a credit line to the material. If material is not included in the article's Creative Commons licence and your intended use is not permitted by statutory regulation or exceeds the permitted use, you will need to obtain permission directly from the copyright holder. To view a copy of this licence, visit http://creativecommons.org/licenses/by/4.0/.

\section{References}

1. Tomić M, Đurišić-Mladenović N, Mićić R, Simikić M, Savin L. Effects of accelerated oxidation on the selected fuel properties and composition of biodiesel. Fuel. 2019;235:269-76.

2. Neuana NF, de Sousa Barboza JC, dos Santos EP, da Silva MLCP (2020) A novel application of Mangifera indica L. and Eugenia uniflora L extracts as antioxidants to control biodiesel oxidation stability. Environ Prog Sustain. Energy.

3. Srinivasa Rao M, Anand RB. Performance and emission characteristics improvement studies on a biodiesel fuelled DICl engine using water and $\mathrm{AlO}(\mathrm{OH})$ nanoparticles. Appl Therm Eng. 2016;98:636-45.

4. García M, Botella L, Gil-Lalaguna N, Arauzo J, Gonzalo A, Sánchez JL. Antioxidants for biodiesel: additives prepared from extracted fractions of bio-oil. Fuel Process Technol. 2017;156:407-14.

5. Lamonica HM. Biodiesel potential of a sugar mill integrated plant using soybean produced in sugarcane renovation fields as feedstock. Energy Sustain Dev. 2008;12:52-5.

6. Sathish Kumar R, Krupa Vara Prasad A. Environment friendly butyl ester biodiesel production from mahua oil: optimization and characterization. SN Appl Sci. 2019;1:1-10.

7. Antony Miraculas G, Bose N, Edwin Raj R. Process parameter optimization for biodiesel production from mixed feedstock using empirical model. Sustain Energy Technol. Assess. 2018;28:54-9.

8. Muhammad C, Mukhtar M, Jibrin M, Jibrin MS, Dabai MU, Sarkin Baki A, Musa U, Dabai A, Sarkin B. Assessment of low temperature refining process of castor seed oil for biodiesel Production characterization and physicochemical properties of biodiesel production from castor oil using refluxed calcined snail shell as catalyst view project biodiesel production. Am J Chem Biochem Eng. 2019;3:1-6.

9. Berman P, Nizri S, Wiesman Z. Castor oil biodiesel and its blends as alternative fuel. Biomass Bioenerg. 2011;35:2861-6.

10. Penabad Sanz L, Rubio Erazo D, Rodríguez Ramos PA, Zumalacárregui de Cárdenas L, Pérez Ones O. Production and environmental impact of Ricinus communis L. oil for biofuel purposes. Dyna. 2019;86:137-42.

11. Mistry U, Thakkar K, Kodgire P, Kachhawaha SS (2019) Biodiesel production from castor seeds (Ricinus communis) oil using Hydrodynamic Cavitation. 3-5.

12. Saribiyik OY, Özcanli M, Serin H, Serin S, Aydin K. Biodiesel production from Ricinus communis oil and its blends with soybean biodiesel. Mech Eng. 2010;56:811-6.

13. Naseem M, Sadaf S, Bibi S, Habib-ur-Rehman Mehmood-ul-Hassan, Aziz S, Ullah I. Evaluation of a NIAB Gold castor variety for biodiesel production and bio-pesticide. Ind Crops Prod. 2019;130:634-41.

14. Pisarello ML, Dalla Costa B, Mendow G, Querini CA. Esterification with ethanol to produce biodiesel from high acidity raw materials: kinetic studies and analysis of secondary reactions. Fuel Process Technol. 2010;91:1005-14.

15. Brunschwig C, Moussavou W, Blin J. Use of bioethanol for biodiesel production. Prog Energy Combust Sci. 2012;38:283-301.

16. Vu DN, Lim O. Experimental study on ignition characteristic of gasoline-biodiesel blended fuel in a constant-volume chamber. J Mech Sci Technol. 2019;33:5073-83.

17. Atabani AE, Silitonga AS, Badruddin IA, Mahlia TMI, Masjuki HH, Mekhilef S. A comprehensive review on biodiesel as an alternative energy resource and its characteristics. Renew Sustain Energy Rev. 2012;16:2070-93.

18. Martinez-Correa HA, Magalhaes PM, Queiroga CL, Peixoto CA, Oliveira AL, Cabral FA. Extracts from pitanga (Eugenia uniflora L.) leaves: influence of extraction process on antioxidant properties and yield of phenolic compounds. J Supercrit Fluids. 2011;55:998-1006.

19. Armendáriz J, Lapuerta M, Zavala F, García-Zambrano E, del Carmen Ojeda M. Evaluation of eleven genotypes of castor oil plant (Ricinus communis L.) for the production of biodiesel. Ind Crops Prod. 2015;77:484-90.

20. Canciam CA. Efeito Da Temperatura Na Viscosidade Dinâmica Dos Óleos Lubrificantes Sae 5W20, Sae 5W30 E Sae 5W40. Rev Da Univ Val Do Rio Verde. 2013;11:228-38

21. Okechukwu RI, Iwuchukwu AC, Anuforo HU. Production and characterization of biodiesel from Ricinus communis Seeds. Res J Chem Sci. 2015;5:2231-606.

22. Keera ST, El Sabagh SM, Taman AR. Castor oil biodiesel production and optimization. Egypt J. Pet. 2018;27:979-84.

23. Ijaz M, Bahtti KH, Anwar Z, Dogar UF, Irshad M. Production, optimization and quality assessment of biodiesel from Ricinus communis L. oil. J Radiat Res Appl Sci. 2016;9:180-4.

24. Miranda RF, Santos ARP, Rezende EH, Faria RQ (2019) Qualidade do biodiesel produzido com grãos de soja armazenados a baixa temperatura Quality of biodiesel produced with soybean grains stored with low temperature

25. Ribas WF, Bilotta P, Janissek PR, Filho MADSC, Neto RAP. Influência do combustível (diesel e biodiesel) e das características da frota de veículos do transporte coletivo de Curitiba, Paraná, nas emissões de NOx. Eng Sanit e Ambient. 2016;21:437-45.

26. Knothe G, Steidley KR. The effect of metals and metal oxides on biodiesel oxidative stability from promotion to inhibition. Fuel Process Technol. 2018;177:75-80. 
27. Kovács A, Tóth J, Isaák G, Keresztényi I. Aspects of storage and corrosion characteristics of biodiesel. Fuel Process Technol. 2015;134:59-64.

28. Cristina A, Akkari S, De Lima EC (2004) Padronização de informações sobre metodologias analíticas para a determinação dos níveis de álcool (etanol) em diferentes amostras biológicas.

29. Ávila Vázquez V, Díaz Estrada RA, Aguilera Flores MM, Escamilla Alvarado C, Correa Aguado HC. Transesterification of non-edible castor oil (Ricinus communis L.) from Mexico for biodiesel production: a physicochemical characterization. Biofuels. 2020;11:753.

Publisher's Note Springer Nature remains neutral with regard to jurisdictional claims in published maps and institutional affiliations. 